Ultratome III, mounted on 150-mesh formvarcoated or 300-mesh uncoated copper grids, stained with lead citrate and uranyl acetate, and examined under the JEM 100C electron microscope. Before ultrathin sectioning $0.5 \mu \mathrm{m}$ sections were cut for light microscopy and stained with periodic acidsilver methenamine.

\section{Results and comments}

Neither the handling of the aspirated tissue sample in the processing device nor the rapid processing had any harmful effect on the glomerular ultrastructure. This was shown for both normal rabbit and normal and diseased human glomeruli. Some of the results are illustrated in Figures 2-5. No difference has been noted in structural integrity between normal and moderately or severely altered tissue in a series of 65 human fine-needle aspiration biopsies. The good structural preservation seems to be favourably influenced by the small size of the aspirate: large specimen size is a known source of fixation and infiltration artefacts (Hayat and Giaquinta, 1970).

The blocks produced with this method had good cutting qualities. The silver to grey coloured sections, mounted on coated or uncoated grids, were stable in the electron beam. The fine-needle aspiration biopsy of the kidney used together with a rapid processing schedule offers a safe, technically simple, and time-saving alternative to conventional biopsy methods in the investigation of human glomerular ultrastructure. The clinical value of the method has been discussed in a previous publication (Pasternack et al., 1977).

\section{References}

Bencosme, S. A., and Tsutsumi, V. (1970). A fast method for processing biologic material for electron microscopy. Laboratory Investigation, 23, 447-450.

Estes, L. W., and Apicella, J. V. (1969). A rapid embedding technique for electron microscopy. Laboratory Investigation, 20, 159-163.

Hayat, M. A., and Giaquinta, R. (1970). Rapid fixation and embedding for electron microscopy. Tissue and Cell, 2, 191-195.

Johannessen, J. V. (1973). Rapid processing of kidney biopsies for electron microscopy. Kidney International, 3, 46-50.

Pasternack, A., Helin, H., and Rantala, I. (1977). Clinical application of renal aspiration biopsy with a modified fine needle. Proceedings of the European Dialysis and Transplant Association, 14, 463-471.

Pasternack, A., Helin, H., Törnroth, T., Rantala, I., Väisänen, J., and Rahka, R. (1978). Aspiration biopsy of the kidney with a new fine needle: a way to obtain glomeruli for morphological study. Clinical Nephrology, 10, 79-84.

Rowden, G., and Lewis, M. G. (1974). Experience with a three-hour electron microscopy biopsy service. Journal of Clinical Pathology, 27, 505-510.

Requests for reprints to: Heikki Helin MD, Department of Biomedical Sciences, University of Tampere, Box 607 , SF-33101 Tampere 10, Finland.

\section{Letter to the Editor}

\author{
Recovery of spores from impregnated \\ filter paper
}

Drs Annear and Green misquote us (Journal of Clinical Pathology, 1979, 32, 93).

Far from stating that quantitative recovery of spores from spore papers was difficult, we described a simple method for doing just that.

It was Kelsey, writing in 1961, who stated that 'Despite repeated attempts no such quantitative recovery technique could be devised'. We referred to this only to show that now at least it is no longer true. P. H. EVERALL and C. A. MORRIS The Royal Shrewsbury Hospital, Shropshire

\section{Reference}

Kelsey, J. C. (1961). The testing of sterilisers. 2. Thermophilic spore papers. Journal of Clinical Pathology, 14, 313-319.

\section{Book reviews}

Recent Advances in Histopathology. Edited by P. P. Anthony and N. Woolf. (Pp. 356: $>$ illustrated; $£ 11 \cdot 00$. Cased edition $£ 15 \cdot 00$. $)$. Edinburgh, London, New York: Living- N stone. 1978.

Most pathologists face recurrent questions of nomenclature, classification, and patho- $\omega$ genesis which they feel should be at their fingertips. Their guilt is now assuaged. With two new editors, 24 contributors, 356 pages (including index), and a paper- $?$ back production the latest Recent Advances $T$ in Histopathology takes care of many of these problems. In this one volume you can get to grips with the evidence for the $\vec{D}$ neuroectodermal origin of the APUD $\cong$ system; compare the sea of classifications 